\title{
A Mass Loss Penetration Model to Investigate the Dynamic Response of a Projectile Penetrating Concrete considering Mass Abrasion
}

\author{
NianSong Zhang, ${ }^{1}$ Dong Wang, ${ }^{2}$ Bei Peng, ${ }^{2}$ and Yong $\mathrm{He}^{1}$ \\ ${ }^{1}$ School of Mechanical Engineering, Nanjing University of Science and Technology, Nanjing, Jiangsu 210094, China \\ ${ }^{2}$ School of Mechatronics Engineering, University of Electronic Science and Technology of China, Chengdu 611731, China \\ Correspondence should be addressed to Bei Peng; beipeng@uestc.edu.cn
}

Received 28 December 2014; Accepted 27 February 2015

Academic Editor: Evangelos J. Sapountzakis

Copyright (c) 2015 NianSong Zhang et al. This is an open access article distributed under the Creative Commons Attribution License, which permits unrestricted use, distribution, and reproduction in any medium, provided the original work is properly cited.

A study on the dynamic response of a projectile penetrating concrete is conducted. The evolutional process of projectile mass loss and the effect of mass loss on penetration resistance are investigated using theoretical methods. A projectile penetration model considering projectile mass loss is established in three stages, namely, cratering phase, mass loss penetration phase, and remainder rigid projectile penetration phase.

\section{Introduction}

Penetration warhead is designed to achieve an effective action on a deep-earth target. Targets are composed of solid materials; as such, high resistance is applied to a penetrator surface during penetration. To improve penetration performance, researchers should consider projectile integrity and ballistic accuracy during structural design. In traditional studies, a penetrator is described as a rigid body without abrasion and deformation. However, with increasing impact velocity, mass abrasion, which changes the shape and the structure of a projectile nose, becomes a major factor affecting the law of motion of projectiles during penetration.

Numerous reviews [1-3] showing the process of penetration and perforation mechanics have been published. For instance, a prediction model of penetration depth has been presented according to spherical cavity expansion theory; predicted results are consistent with penetration depth and complete deceleration response until excessive nose erosions occur [4-8]. In other studies, a prediction model has been established on the basis of cavity shape according to cylindrical [9] and spherical [5] cavity expansion theories as expressed by cylindrical and spherical coordinates, respectively. These coordinates can also be expressed as single format $[10,11]$. Further studies have considered time effect in model designs based on dynamic and static cavity expansion theories. Moreover, models have been constructed with different coordinates by Lagrangian and Eulerian coordinate analysis, as well as different target response regions, including elastic-crack-fracture response $[12,13]$ and elasticcrack-plastic response [14]. In other models, different target materials, such as compressible and incompressible materials, as well as shear hardening and exponential hardening models [15], have been used. In other studies, strength model has been established according to different theories, such as Mohr-Coulomb strength theory, unified strength theory [16, 17], and Griffith strength theory [10].

Chen and Li $[18,19]$ systematically studied the process by which a rigid projectile is launched into concrete at a low velocity, analyzed normal penetration and oblique penetration [20], and presented the third dimensionless number, which controls rigid penetration kinetics [21]. Thus, the three-stage dimensionless numbers are impact function $I$, nose shape function $N$, and dimensionless mass. Chen et al. [22-24] further presented a structural design 
of a low-velocity kinetic projectile and performed relevant experiments [25].

Silling and Forrestal [26] fitted ogive-nose projectile penetrating into a concrete target composed of quartz and limestone aggregates at a striking velocity of approximately $1000 \mathrm{~m} / \mathrm{s}$; the findings reveal a linear dependence of mass loss versus initial kinetic energy; moreover, a mass abrasion model is established from a projectile surface. In further studies, an abrasion model is applied to a Sandia developed, Eulerian hydrocode CTH [27]; predictions are in good agreement with experimental observations.

Gerlach [28] and Shockey et al. [29] described mass loss penetration in terms of tungsten alloy penetrating a steel target and a concrete target. Gerlach [28] indicated that the remainder of a projectile is corroded by black micromechanism, and heavy mental particles adhere to the end of the projectile. Shockey et al. [29] investigated the variation in shape of the nose of a tungsten alloy and revealed that nose shape changes between mushroom- and pencil-like structures several times during penetration. Forrestal et al. $[4,5]$ used a 4340 steel projectile penetrating a concrete target at velocities of $350 \mathrm{~m} / \mathrm{s}$ to $1200 \mathrm{~m} / \mathrm{s}$. Forrestal et al. $[4,5]$ also utilized projectiles with different sizes $(12.9,20.3$, and $30.5 \mathrm{~mm}$ ) to strike concrete targets, which exhibit different axial compressive strengths; as striking velocity increases, nose abrasion becomes evident until bending or cracking occurs. Frew et al. [30] obtained similar mass abrasion experimental data regarding an ogive-nose projectile penetrating a steel-reinforced concrete target. In the previous study [30], ogive-nose projectiles are allowed to penetrate concrete targets composed of limestone and quartz aggregates at impact velocities of $400 \mathrm{~m} / \mathrm{s}$ to $1200 \mathrm{~m} / \mathrm{s}$; penetration depths and mass abrasion ratio are then obtained. The results demonstrate that mass abrasion depends on the hardness of a projectile and a target. At an impact velocity of $1200 \mathrm{~m} / \mathrm{s}$ to $1500 \mathrm{~m} / \mathrm{s}$, mass abrasion may induce an unstable terminal ballistics; thus, a projectile is damaged. Considering that abrasion occurs as a result of the melting of a projectile surface and the removal of a portion of this melted surface layer, Beissel assumed that the rate of work done on the projectile by the surface normal component of stress is insignificant compared with that done by the tangential component of stress.

Beissel and Johnson [31] also presented a three-dimensional abrasion algorithm, in which incremental adjustments to a Lagrangian finite-element mesh are used to implement abrasion rate. This algorithm shows a high degree of agreement between the $3 \mathrm{D}$ implementation and $2 \mathrm{D}$ axisymmetric implementation; however, this algorithm appears as a result of the value chosen as the proportionality constant in the abrasion rate, not abrasion algorithm.

Studies have mostly based abrasion on data fitting, but these data cannot distinguish mass losses between the nose and the body of a projectile. In this paper, our projectile penetration model based on mass loss is established in three stages, namely, cratering phase, mass loss penetration phase, and remainder rigid projectile penetration phase. Our study reveals that penetration depth decreases as the ratio of mass abrasion on nose increases.

\section{Mass Loss Penetration Model}

2.1. Description of Penetration Process. According to Newton's second law, the parameters of penetration could be calculated on the basis of the relationship among resistance, mass, and velocity. The projectile can be considered as a rigid body at low velocities. At high velocities, penetration occurs with mass loss; as such, the physical model is divided into three stages: cratering phase, mass loss penetration phase, and remainder rigid projectile penetration phase (Figure 1).

Cratering phase occurs for a short period; thus, mass abrasion and deformation could be ignored, and penetrating process can be approximately regarded as a rigid model. In mass abrasion penetration phase, the surface material on the nose of projectile melts and falls off; as a result, mass loss is observed. Remainder rigid projectile penetration phase occurs immediately after mass loss penetration phase is completed.

Nose evolutional law could be used to infer the penetration results. Nose mass is approximately $10 \%$ of the entire projectile, and a slight change in mass likely causes a significant variation in nose shape; therefore, nose abrasion must be considered. We introduced $\omega$, which is the ratio of nose mass loss to projectile mass loss expressed as $\omega \in(0,1)$.

\subsection{Derivation of Basic Equations}

2.2.1. Projectile Mass Abrasion Equation. The three-phase mass change model is illustrated in Figure 2.

The governing equations of the three stages are expressed as follows:

$$
m= \begin{cases}m_{0}, & V_{1} \leq V_{z} \leq V_{s}, \\ m_{f}\left(V_{z}\right), & V_{c}<V_{z} \leq V_{1}, \\ m_{r}, & V_{z} \leq V_{c},\end{cases}
$$

where $V_{1} \leq V_{z} \leq V_{s}$ is the cratering phase; $m_{0}$ is the initial projectile mass; $V_{c}<V_{z} \leq V_{1}$ is mass loss penetration phase; and mass change is $m_{f}\left(V_{z}\right)$. Mass stops changing when $V_{z} \leq V_{c}$; the remainder mass of the projectile is $m_{r} ; V_{s}$ is the initial striking velocity; $V_{1}$ is the velocity at the end of cratering phase; and $V_{c}$ is the velocity at the end of mass loss penetration phase.

The mass loss ratio $\Delta m / m_{0}$ is related to the striking velocity $V_{s}$ and written as a form of a totally quadratic polynomial:

$$
\frac{\Delta m}{m_{0}}=\frac{m_{0}-m_{f}}{m_{0}}=E_{1} V_{s}^{2}+E_{2} V_{s}+E_{3} .
$$

Consider $\omega=1$ and $E_{2}=E_{3}=0$; we obtain $\Delta m / m_{0}=$ $1 / 2 E_{1} V_{s}^{2}[26,32-34]$. When $E_{1}=0, \Delta m / m_{0}$ is deduced as $\Delta m / m_{0}=E_{2} V_{s}+E_{3}$ [34]; thus, we suggested that mass loss is related to the initial momentum and the mass of the projectile. 


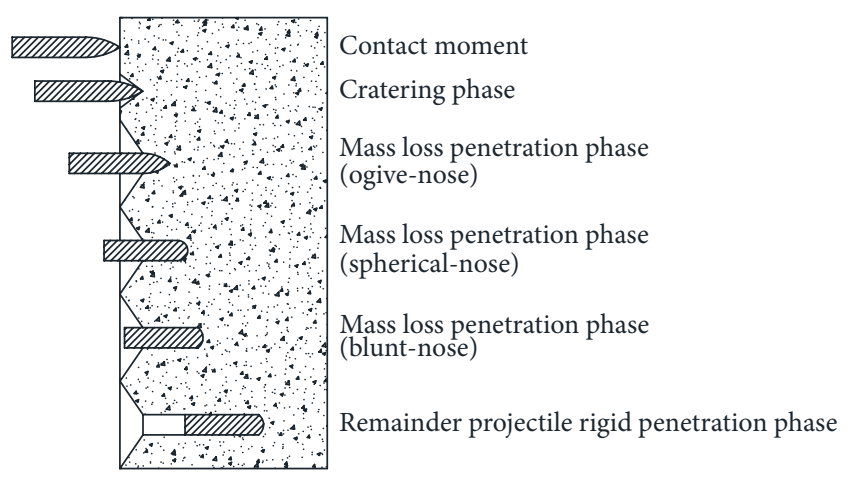

FIGURE 1: Sketch map of three-phase penetration.

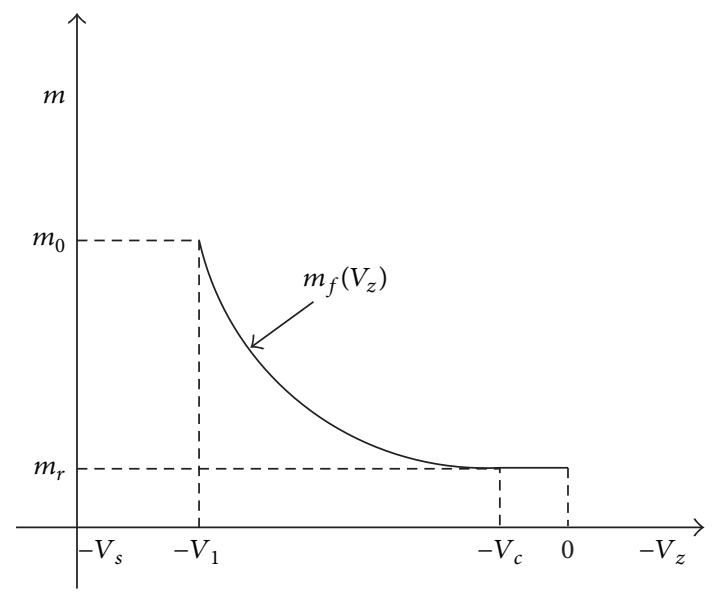

FIGURE 2: Projectile mass abrasion model.

At the end of the mass loss phase, we derived $E_{1} V_{c}^{2}+E_{2} V_{c}+$ $E_{3}=0$ and obtained the mass abrasion model, as expressed in the following equation:

$$
\begin{array}{r}
m_{f}\left(V_{z}\right)=m_{0}\left[1-E_{1}\left(V_{s}^{2}-V_{z}^{2}\right)-E_{2}\left(V_{s}-V_{z}\right)\right], \\
V_{c} \leq V_{z} \leq V_{s} .
\end{array}
$$

The mass of the projectile is $m<m_{0}$ when $V_{z}=V_{1}$. Thus, mass loss ratio equation is revised as follows:

$$
\begin{gathered}
\frac{\Delta m}{m_{0}}=\frac{m_{0}-m_{f}}{m_{0}}=F_{1} V_{1}^{2}+F_{2} V_{1}+F_{3} \\
\frac{\omega \Delta m}{m_{0}}=\frac{\omega\left(m_{0}-m_{f}\right)}{m_{0}}=\frac{m_{0}-m_{t f}}{m_{0}}=G_{1} V_{1}^{2}+G_{2} V_{1}+G_{3} .
\end{gathered}
$$

In (4b), the coefficient $\omega$ is introduced.

Resistance equation is derived from Forrestal's model [4]:

$$
F_{z}= \begin{cases}c z, & 0 \leq z \leq 4 a \\ \pi a^{2}\left(S f_{c}^{\prime}+N \rho_{t} V_{z}^{2}\right), & z>4 a\end{cases}
$$

where $a$ is the projectile radius; $f_{c}^{\prime}$ is the axial compression strength of the target; $\rho_{t}$ is the density of the target;
$N$ is the shape coefficient; and $S$ is the dimensionless target parameter expressed as $S=82.6 f_{c}^{\prime-0.544}$.

The resistance coefficient in cratering phase is expressed as follows [4]:

$$
c=\frac{m\left(V_{s}^{2}-V_{1}^{2}\right)}{16 a^{2}} \text {. }
$$

The square of penetration velocity at the end of the cratering phase is presented as follows [4]:

$$
V_{1}^{2}=\frac{m_{0} V_{s}^{2}-4 \pi a^{3} S f_{c}^{\prime}}{m_{0}+4 \pi a^{3} N_{0} \rho_{t}} .
$$

Mass change equations are given by $(8 \mathrm{~b})$ :

$$
\begin{array}{r}
m_{f}\left(V_{z}\right)=m_{0}\left[1-F_{1}\left(V_{1}^{2}-V_{z}^{2}\right)-F_{2}\left(V_{1}-V_{z}\right)\right], \\
V_{c} \leq V_{z} \leq V_{1}, \\
m_{t f}\left(V_{z}\right)=m_{0}\left[1-G_{1}\left(V_{1}^{2}-V_{z}^{2}\right)-G_{2}\left(V_{1}-V_{z}\right)\right], \\
V_{c} \leq V_{z} \leq V_{1} .
\end{array}
$$

2.2.2. Mass Loss Leads to Variation in Caliber-Radius-Head $(\mathrm{CRH})$. When the initial nose shape is ogive, the relational equation of remainder projectile mass and volume is expressed as follows:

$$
m_{t f}=\rho_{p} V_{f}=\pi \rho_{p} a^{2}\left(k_{f} a+L\right)
$$

where $L$ is the initial length of the projectile; $k_{f}$ is the nose length convert coefficient of the remainder projectile; $k_{f}$ of ogive-nose [35], spherical-nose, blunt-nose [35], and flatnose are given by

$$
\begin{array}{r}
k_{f}=8 \psi_{f}^{3}\left[\sqrt{\frac{1}{\psi_{f}}-\frac{1}{4 \psi_{f}^{2}}}\left(1-\frac{1}{3 \psi_{f}}+\frac{1}{12 \psi_{f}^{2}}\right)\right. \\
\left.-\left(1-\frac{1}{2 \psi_{f}}\right) \arccos \left(1-\frac{1}{2 \psi_{f}}\right)\right], \\
k_{f}=\frac{2}{3}, \\
k_{f}=\frac{16}{3} \psi_{f}^{3}\left[1-\sqrt{1-\frac{1}{4 \psi_{f}^{2}}}\left(1+\frac{\psi_{f}}{8}\right)\right], \\
k_{f}=-\frac{l}{a},
\end{array}
$$

where $l$ is the shortened length measured after nose shape transformed from ogive to flat.

Nose shape coefficients change during penetration process. For ogive-, sphere-, and blunt-nose, even flat-nose, 
the nose shape coefficients of the remainder projectile are expressed in the following equations [21]:

$$
\begin{gathered}
N_{f}=\frac{8 \psi_{f}-1}{24 \psi_{f}^{2}}, \\
N_{f}=\frac{1}{2}, \\
N_{f}=1-\frac{1}{8 \psi_{f}^{2}}, \\
N_{f}=1 .
\end{gathered}
$$

\subsubsection{Projectile Penetration Equations}

(1) Cratering Phase $\left(V_{1} \leq V_{z} \leq V_{s}, 0 \leq z \leq 4 a\right.$, $\left.m=m_{0}\right)$. This stage occurs for a short period; if the mass of the projectile remains unchanged, then the governing equation is presented as follows [4]:

$$
m_{0} \frac{d V_{z}}{d t}=F_{z}=-c z,
$$

where $c$ is calculated by (6) and $V_{1}$ is calculated by (7).

(2) Mass Loss Penetration Phase $\left(V_{c} \leq V_{z} \leq V_{1}, z>4 a, m=\right.$ $\left.m_{f}\right)$. Mass abrasion in this phase causes variation in nose shape and $\mathrm{CRH}$; mass abrasion also influences nose shape coefficients. Thus, the governing equation is written as follows [4]:

$$
\begin{aligned}
m_{f} \frac{d V_{z}}{d t} & =m_{0}\left[1-F_{1}\left(V_{1}^{2}-V_{z}^{2}\right)-F_{2}\left(V_{1}-V_{z}\right)\right] \frac{d V_{z}}{d t} \\
& =-\pi a^{2}\left(S f_{c}^{\prime}+N_{f} \rho_{t} V_{z}^{2}\right) .
\end{aligned}
$$

We then compared the mass of the remainder projectile $m_{f}$ with that of the spherical-nose projectile ((9) and (10b)); we also calculated $\mathrm{CRH}$ and nose shape coefficients, where $N_{f}$ is the remainder projectile nose shape coefficient obtained by (11a)-(11d), and $\psi_{f}$ is the CRH of the remainder projectile expressed in (9) and (10a)-(10d). Thus, the quadratic polynomial form of $V_{c}$ is expressed as follows:

$$
F_{1} V_{c}^{2}+F_{2} V_{c}+F_{3}=0
$$

(3) Remainder Rigid Projectile Penetration Phase $\left(V_{z} \leq\right.$ $V_{c}, z>4 a, m=m_{r}$ ). In this phase, the mass of a projectile remains unchanged, and $m_{r}$ can be expressed as follows [4]:

$$
m_{r}=m_{0}\left[1-F_{1}\left(V_{1}^{2}-V_{c}^{2}\right)-F_{2}\left(V_{1}-V_{c}\right)\right] .
$$

The nose shape is the same as that in the second phase; $\psi_{r}$ is $\mathrm{CRH}$, and $N_{r}$ is nose shape coefficient; the governing equation is written as follows [4]:

$$
m_{r} \frac{d V_{z}}{d t}=-\pi a^{2}\left(S f_{c}^{\prime}+N_{r} \rho_{t} V_{z}^{2}\right)
$$

2.3. Calculation Method of Penetration Depth. According to the description of penetration governing equation, the equation of DOP cannot be expressed by explicit formulation; instead, the equation of DOP should be calculated iteratively:

(1) After penetration data are fitted, the coefficients $F_{i}$ and $G_{i}(i=1,2,3)$ are obtained using $(4 \mathrm{a})$ and $(4 \mathrm{~b})$.

(2) Consider $V_{z} \in\left[V_{s} V_{1}\right]$; the coefficients of cratering phase are calculated using (12).

(3) Consider $V_{z} \in\left[V_{1} V_{c}\right]$; the coefficients of mass loss penetration phase are calculated using (13).

(4) Consider $V_{z} \in\left[V_{c} 0\right]$; the coefficients of remainder projectile penetration phase are calculated using (14).

Figure 3 shows the flow chart of the iterative calculation of penetration depth considering mass abrasion.

\section{Results}

3.1. Quadratic Polynomial Coefficients of Mass Loss Rate. According to the discussion of Section 2.2.1, we calculate the coefficients of the quadratic polynomial of mass change rate (Table 1) and plot the data fitting curve in Figure 4. Our results show that projectile velocity at the end of cratering phase is related to the final mass loss rate. We compared the experimental data with quadratic polynomial fitting and linear fitting; our results reveal that quadratic polynomial data agrees with the experimental data at a greater extent than linear data.

3.2. Calculations of Final Nose Shape. According to the discussion of Section 2.2.2, the calculations and experimental data of the final nose shape are presented in Figure 5, where $\psi_{r}$ is the final CRH.

Figure 5 shows that our calculations agree well with experimental data; this result indicates that projectile mass loss is mainly attributed to nose abrasion. Our calculations also reveal that $\mathrm{CRH}$ decreases as initial impact velocity increases; nose shape is also transformed from an ogive-like structure to sphere- or blunt-like structure. The nose shape coefficients expressed in (5) change because of the variation in nose shape and $\mathrm{CRH}$; thus, penetration resistance varies. With this variation, velocity, acceleration, and the relationship between DOP and initial impact velocity also change.

3.3. Calculations of Penetration Depth. According to the discussion of Section 2.3, detailed calculations are shown in Figure 6 and Table 2. Figure 6 illustrates the comparison of the two conditions. With our calculations, rigid penetration results and those of different $\omega$ values are compared. Table 2 lists the comparison results of mass loss and penetration, as well as the calculated results of penetration depth for $\omega=0.6$, $0.7,0.8$.

Figure 6 shows that the two models agree with the experimental observations in a low-velocity phase; by contrast, the mass loss model fits the experimental data better than the other model in a high-velocity phase. Furthermore, the DOP of the mass loss model unlikely increases as impact velocity increases. Figure 6 illustrates the results of abrasion 

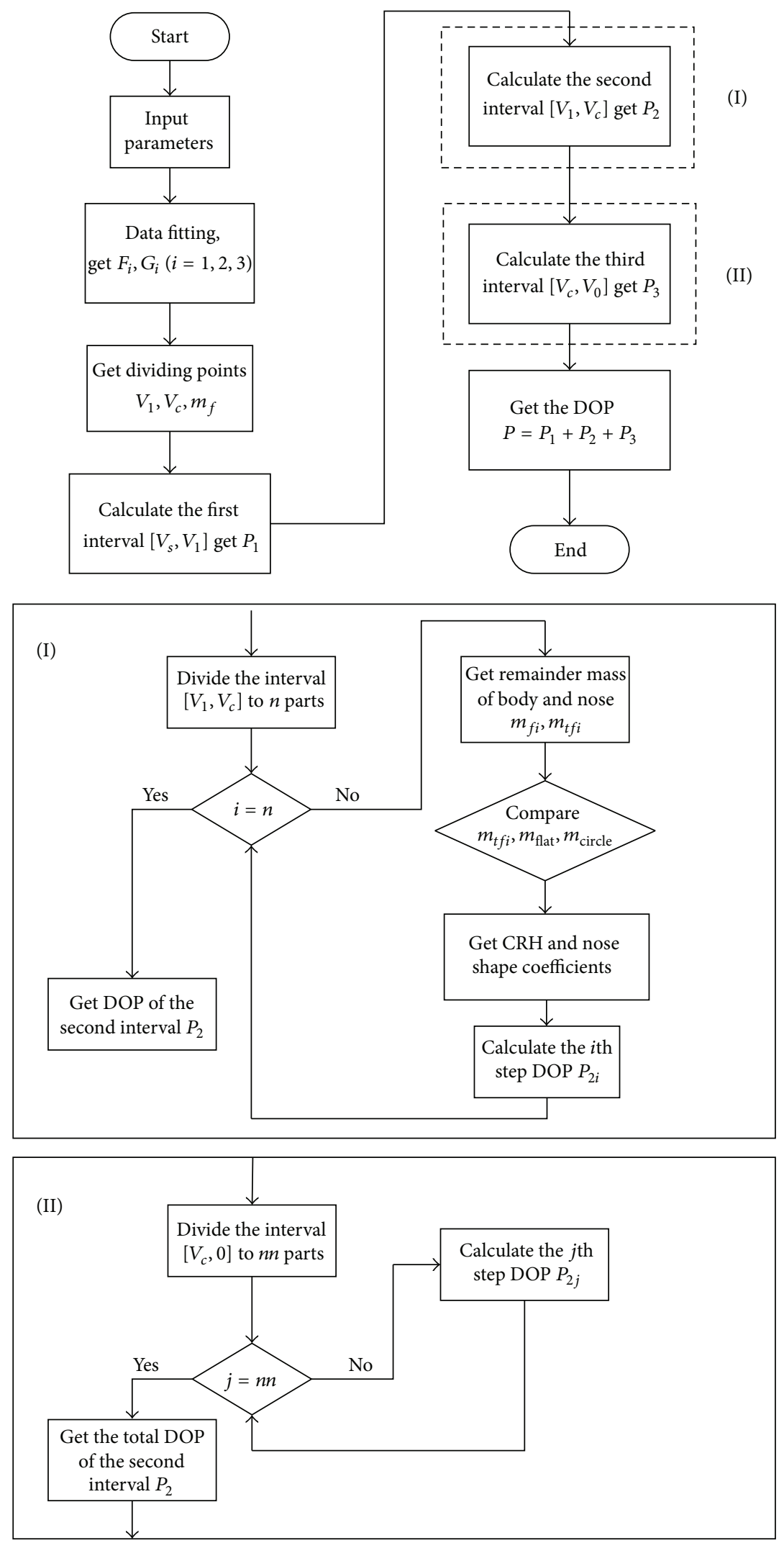

FIGURE 3: Flow chart of the iterative calculation of penetration depth considering mass abrasion. 
TABLE 1: Quadratic polynomial coefficients of mass loss rate $(\omega=1)$.

\begin{tabular}{lccccc}
\hline & Projectile diameter/mm & Target strength/MPa & $F_{1} / G_{1}$ & $F_{2} / G_{2}$ & $F_{3} / G_{3}$ \\
\hline Condition 1 & 20.3 & 62.8 & $3.98 E-8$ & $6.01 E-5$ & $-1.125 E-2$ \\
Condition 2 & 30.5 & 51 & $-4.1 E-8$ & $1.5 E-4$ & $-3.319 E-2$ \\
\hline
\end{tabular}

TABLE 2: Comparison of experimental data and our calculated data.

\begin{tabular}{|c|c|c|c|c|c|c|c|}
\hline \multirow{3}{*}{$\begin{array}{l}\text { Number of } \\
\text { experiment }\end{array}$} & \multirow{3}{*}{ Initial velocity $/ \mathrm{m} / \mathrm{s}$} & \multicolumn{2}{|c|}{ Mass loss $/ \%$} & \multirow{2}{*}{\multicolumn{4}{|c|}{$\begin{array}{l}\mathrm{DOP} / \mathrm{m} \\
\text { Computational results in } \\
\text { different values of } \omega\end{array}$}} \\
\hline & & \multirow[t]{2}{*}{$\begin{array}{l}\text { Experimental } \\
\text { results }\end{array}$} & \multirow[t]{2}{*}{$\begin{array}{l}\text { Computational } \\
\text { results }\end{array}$} & & & & \\
\hline & & & & $\begin{array}{l}\text { Experimental } \\
\text { results }\end{array}$ & 0.6 & 0.7 & 0.8 \\
\hline \multirow{6}{*}{1} & 450 & 1.5 & 1.86 & 0.3 & 0.281 & 0.281 & 0.281 \\
\hline & 612 & 2.7 & 3.31 & 0.48 & 0.483 & 0.482 & 0.482 \\
\hline & 821 & 4.5 & 5.48 & 0.76 & 0.794 & 0.791 & 0.788 \\
\hline & 926 & 5.5 & 6.70 & 0.95 & 0.962 & 0.956 & 0.950 \\
\hline & 987 & 6.6 & 7.45 & 0.92 & 1.060 & 1.052 & 1.043 \\
\hline & 1024 & 6.2 & 7.91 & 0.94 & 1.120 & 1.110 & 1.098 \\
\hline \multirow{10}{*}{2} & 405 & 1.2 & 1.84 & 0.37 & 0.374 & 0.374 & 0.374 \\
\hline & 446 & 1.5 & 2.33 & 0.42 & 0.442 & 0.442 & 0.441 \\
\hline & 545 & 2 & 3.45 & 0.56 & 0.626 & 0.624 & 0.622 \\
\hline & 651 & 3.1 & 4.45 & 0.78 & 0.845 & 0.841 & 0.836 \\
\hline & 804 & 4.7 & 5.9 & 1.05 & 1.186 & 1.174 & 1.160 \\
\hline & 821 & 4.4 & 6.08 & 1.23 & 1.225 & 1.211 & 1.195 \\
\hline & 900 & 5.4 & 6.71 & 1.41 & 1.404 & 1.382 & 1.357 \\
\hline & 1009 & 6.4 & 7.50 & 1.75 & 1.644 & 1.606 & 1.564 \\
\hline & 1069 & 7 & 7.88 & 1.96 & 1.771 & 1.721 & 1.669 \\
\hline & 1201 & 6.8 & 8.64 & 2.03 & 2.028 & 1.948 & 1.869 \\
\hline
\end{tabular}

\footnotetext{
${ }^{1}$ The number of the first experiment shown in Figure 6(a).
}

${ }^{2}$ The number of the second experiment shown in Figure 6(b).

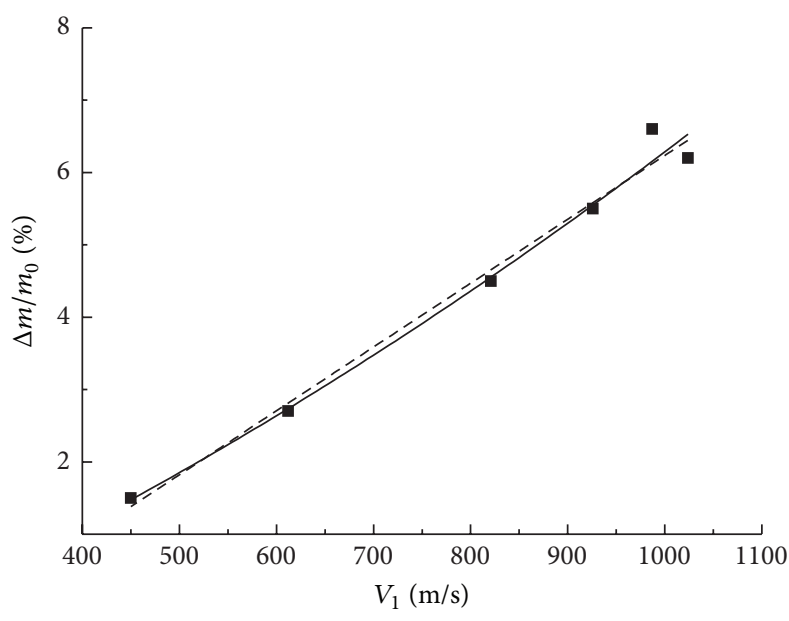

- Experimental data

Polynomial fit

- - - Linear fit

(a) Projectile diameter $20.3 \mathrm{~mm}$; target strength $62.8 \mathrm{MPa}$

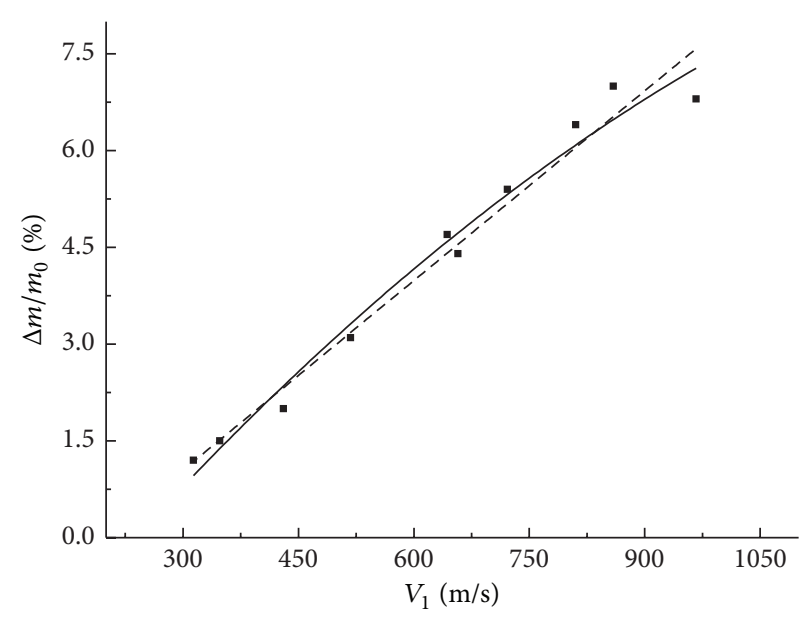

- Experimental data

Polynomial fit

- - - Linear fit

(b) Projectile diameter $30.5 \mathrm{~mm}$; target strength $51 \mathrm{MPa}$

FIgURE 4: Fittings of mass loss penetration experimental data. 




(a) Projectile diameter $20.3 \mathrm{~mm}$; target strength $62.8 \mathrm{MPa}$

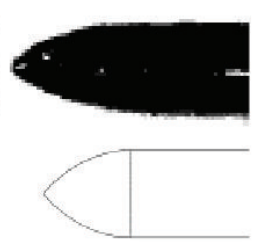

$405 \mathrm{~m} / \mathrm{s}$;

ogive-nose;

$\psi_{r}=2.336$



$821 \mathrm{~m} / \mathrm{s}$

ogive-nose;

$\psi_{r}=0.989$



$446 \mathrm{~m} / \mathrm{s}$;

ogive-nose;

$\psi_{r}=2.184$
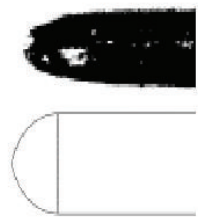

$900 \mathrm{~m} / \mathrm{s}$;

ogive-nose;

$\psi_{r}=0.694$

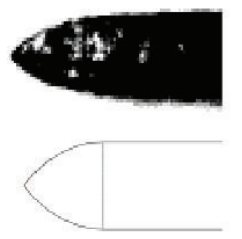

$545 \mathrm{~m} / \mathrm{s}$;

ogive-nose;

$\psi_{r}=1.942$
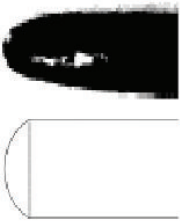

$1009 \mathrm{~m} / \mathrm{s}$;

blunt-nose

$\psi_{r}=0.547$

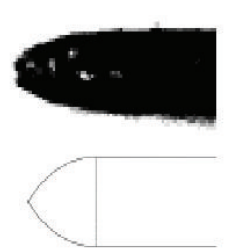

$651 \mathrm{~m} / \mathrm{s}$;

ogive-nose;

$$
\psi_{r}=1.462
$$
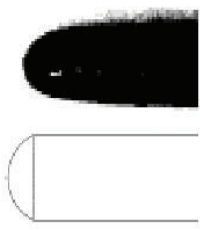

$1069 \mathrm{~m} / \mathrm{s}$

blunt-nose;

$\psi_{r}=0.574$

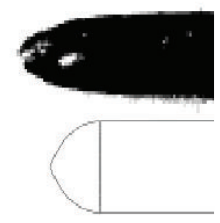

$804 \mathrm{~m} / \mathrm{s}$;

ogive-nose; $\psi_{r}=0.894$
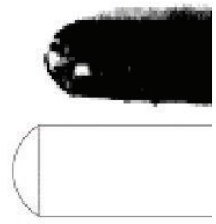

$1201 \mathrm{~m} / \mathrm{s}$;

blunt-nose;

$\psi_{r}=0.564$

(b) Projectile diameter $30.5 \mathrm{~mm}$; target strength $51 \mathrm{MPa}$

FIGURE 5: Comparison of final nose shape calculations and experimental result for $\omega=1$.

model compared with those of a rigid penetration model by controlling the value of $\omega$; the mass abrasion model is close to the rigid penetration model when $\omega \rightarrow 0$. Figure 6 reveals that penetration depth decreases as $\omega$ decreases and striking velocity remains constant. Figure 6 and Table 2 indicate that the calculations are consistent with the experimental data of DOP when nose-body abrasion ratio is 0.6 to 0.8 ; this result suggests that nose mass loss is approximately $60 \%$ to $80 \%$ of body mass loss. For the condition shown in Figure 6(a), the DOP is $1.8 \mathrm{~m}$ when $\omega=0.8$. For the condition presented in Figure $6(\mathrm{~b})$, the DOP is $2.8 \mathrm{~m}$ when $\omega=0.6$.

\section{Discussion}

4.1. Influencing Factors of Penetration Depth. This paper focuses on the difference between mass loss penetration model and rigid projectile penetration model after the cratering phase is completed. The discussion in succeeding sections focuses on mass loss penetration phase and remainder projectile penetration phase.

From the governing equations of the two models, (13) and (16), changes in mass and resistance yield distinct penetration results. The resistance factors include nose shape 


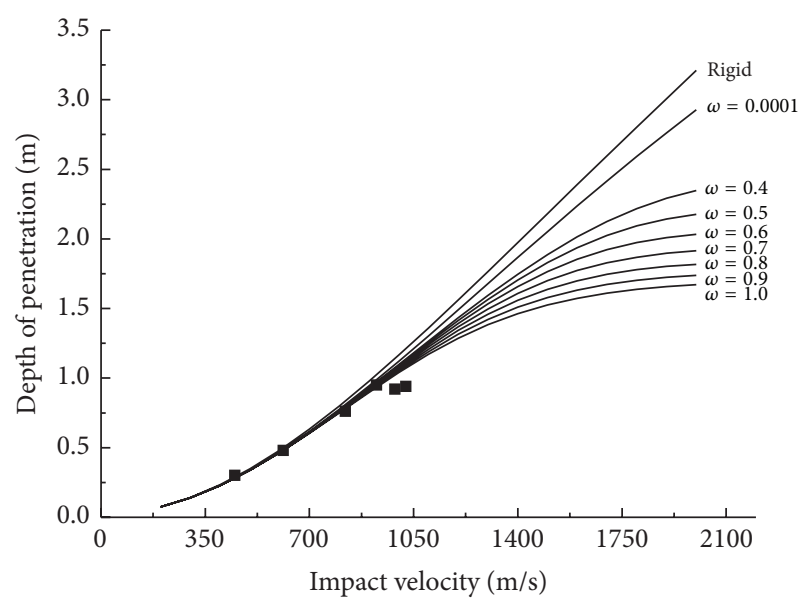

- Experimental data Calculation

(a) Projectile diameter $20.3 \mathrm{~mm}$; target strength $62.8 \mathrm{MPa}$

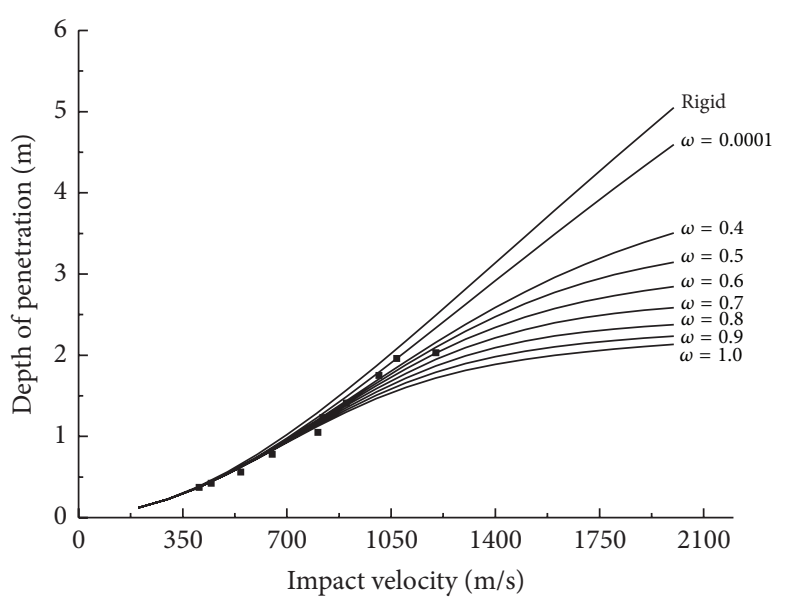

- Experimental data Calculation

(b) Projectile diameter $30.5 \mathrm{~mm}$; target strength $51 \mathrm{MPa}$

FIGURE 6: Comparison of DOP experimental results and models.

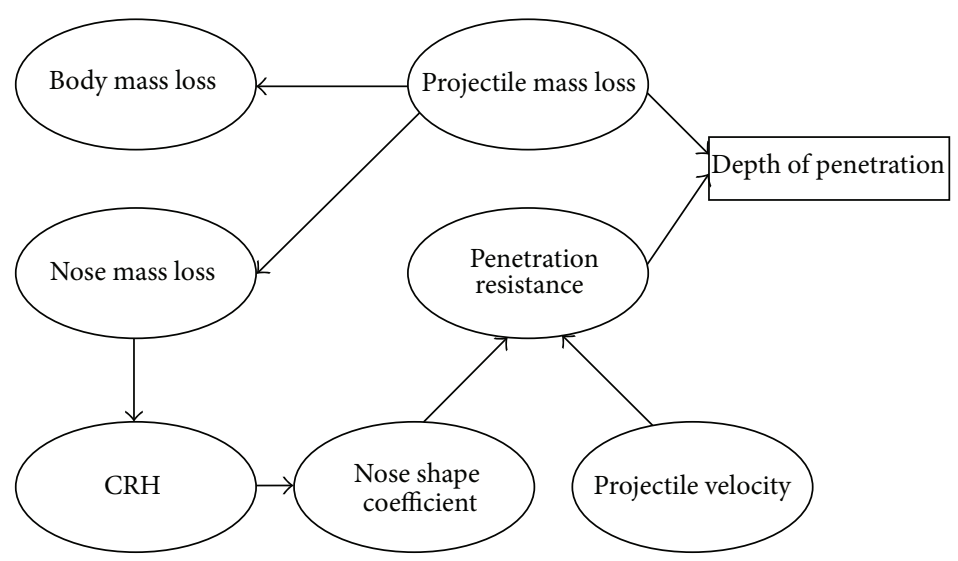

FIGURE 7: DOP factors.

coefficients and projectile velocity. Using (8b), (9), and (11a)(11d), we found that nose shape coefficients are influenced by nose mass loss and nose deformation. Figure 7 shows the influencing factors of DOP.

4.2. Influencing Factors of Mass Loss. Let us define simple projectile mass loss, which only involves mass abrasion without considering the variation in nose shape coefficients.

(1) For the two conditions illustrated in Figure 8, the results are almost similar at low velocity; as velocity increases, the result of mass abrasion model is lower than that of simple mass loss, indicating that simple projectile mass loss has influences on penetration depth.

(2) For the two conditions presented in Figure 8, the difference between the two models is small; this result indicates that the effect of simple projectile mass loss is not significant.
4.3. Analysis of Penetration Resistance. The effect of mass abrasion on penetration depth is not significant. Penetration resistance is the main factor. To study resistance evolutional law, we determine penetration resistance at velocities of $821 \mathrm{~m} / \mathrm{s}$ and $1201 \mathrm{~m} / \mathrm{s}$. Figure 9 shows the calculations of penetration resistance after cratering phase is completed for the mass abrasion model and rigid penetration model. To show the decrease in velocity, we consider the opposite direction of a projectile velocity along the $x$ axis as positive. $V_{1}$ and $V_{\mathrm{c}}$ are the dividing velocities of the three stages. The second part $\left[V_{1}, V_{c}\right]$ is the mass loss penetration phase and the third part $\left[V_{c}, 0\right]$ is the remainder projectile penetration phase.

Figure 9 shows that at impact velocities of $821 \mathrm{~m} / \mathrm{s}$ and $1201 \mathrm{~m} / \mathrm{s}$ the resistance of mass loss model is larger than that of rigid model; as such, the mass loss model fits our experimental data better than the rigid model. Resistance increases as $\omega$ increases; thus, DOP decreases. The resistance of rigid penetration and that of $\left[V_{c}, 0\right]$ decrease as velocity decreases. Nose shape coefficients remain unchanged under 




- Experimental data

- - $m_{f} ; \omega=0.8$

$m_{0} ; \omega=0.8$

(a) Projectile diameter $20.3 \mathrm{~mm}$; target strength $62.8 \mathrm{MPa}$

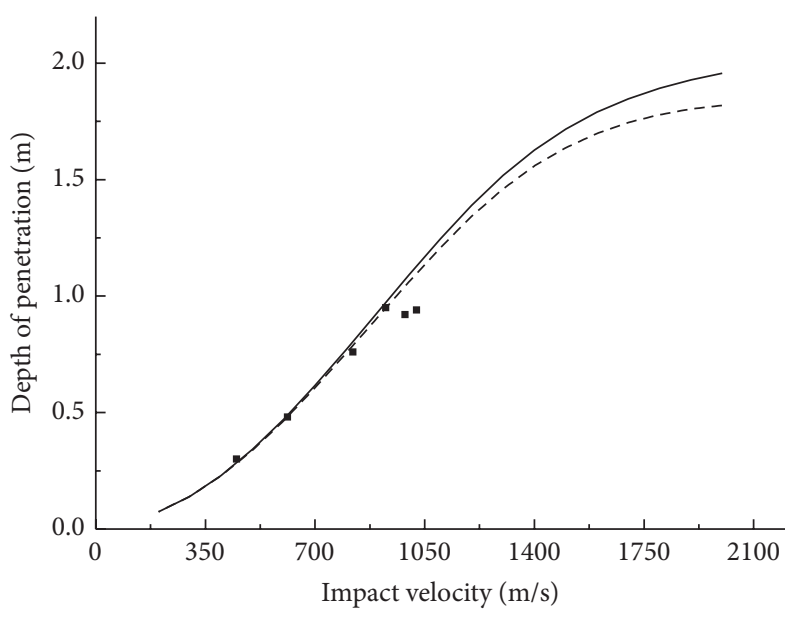

- Experimental data

- - $m_{f} ; \omega=0.8$

$m_{0} ; \omega=0.8$

(b) Projectile diameter $30.5 \mathrm{~mm}$; target strength $51 \mathrm{MPa}$

FIGURE 8: Comparison of calculations between mass abrasion model and simple mass loss model.

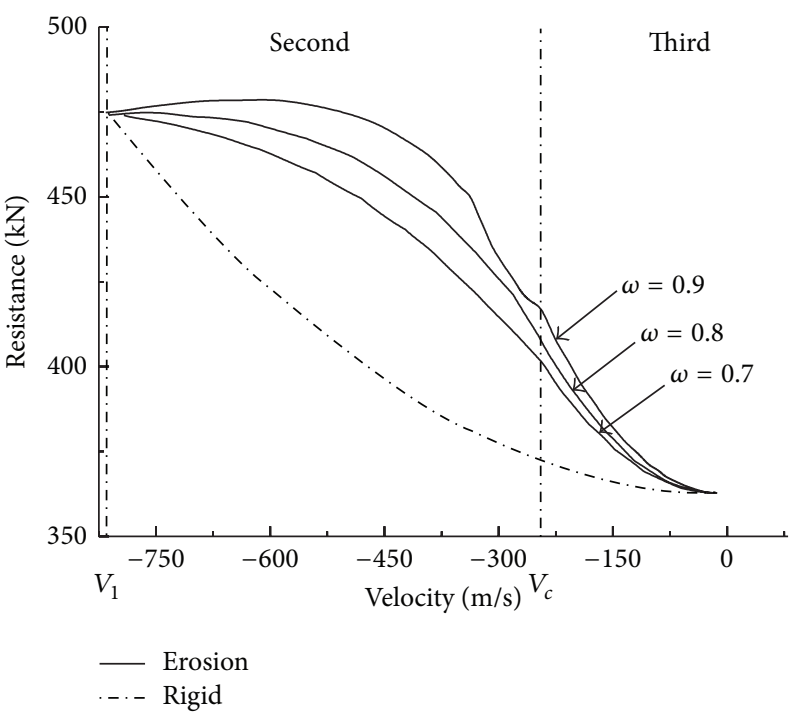

(a) $V_{s}=821 \mathrm{~m} / \mathrm{s}$

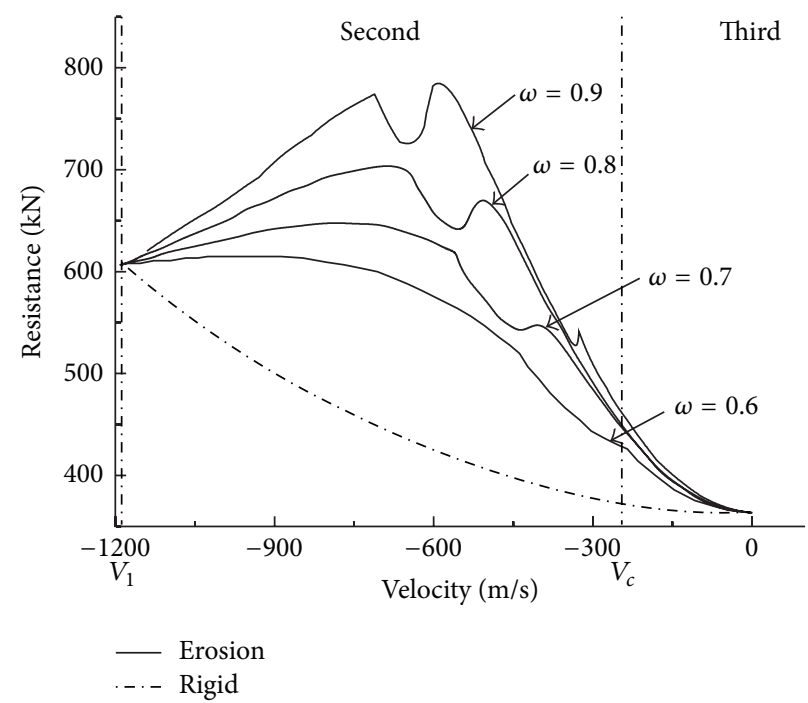

(b) $V_{s}=1201 \mathrm{~m} / \mathrm{s}$

FIGURE 9: Variation in resistance after cratering phase.

this condition; thus, velocities are the main factors that change resistance. In $\left[V_{1}, V_{c}\right]$, resistance decreases as velocity decreases only in low-velocity phase; thus, penetration velocity is not the only factor that influences resistance. Furthermore, in the second part of the interval, the curve of resistance is irregular with double peaks.

4.4. Influencing Factors of Nose Shape Coefficients. Using (11a)-(11d), we can determine the coefficients of a projectile nose shape based on nose shape and CRH. To describe the variation pattern of nose shape coefficients in diagram, we use the following parameters: for ogive-nose and spherical-nose, the value of $x$ axis is $\varphi_{f}^{\prime}=0.5-\varphi_{f}$; for blunt-nose, the value of $x$ axis is $\varphi_{f}^{\prime}=\varphi_{f}-0.5$ (Figure 10). Thus, the initial ogive-nose coefficient is the minimum value of the total penetration process. With mass abrasion, the CRH and the shape coefficient of ogive-nose increase until the shape of the nose changes to sphere and the shape coefficient is 0.5. The shape of the nose further changes to blunt; as such, the relationship between nose shape coefficient and CRH changes. In particular, the curve becomes steep until nose shape coefficient is approximately equal to 1 . If velocity is still nonzero, nose shape coefficient is considered equal to 1 . 


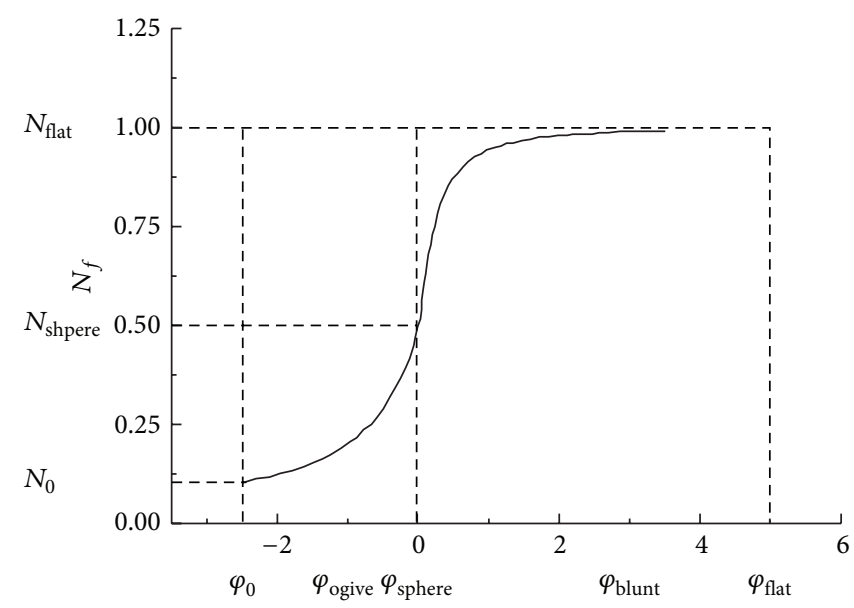

FIGURE 10: Nose shape coefficient versus nose shape and CRH.

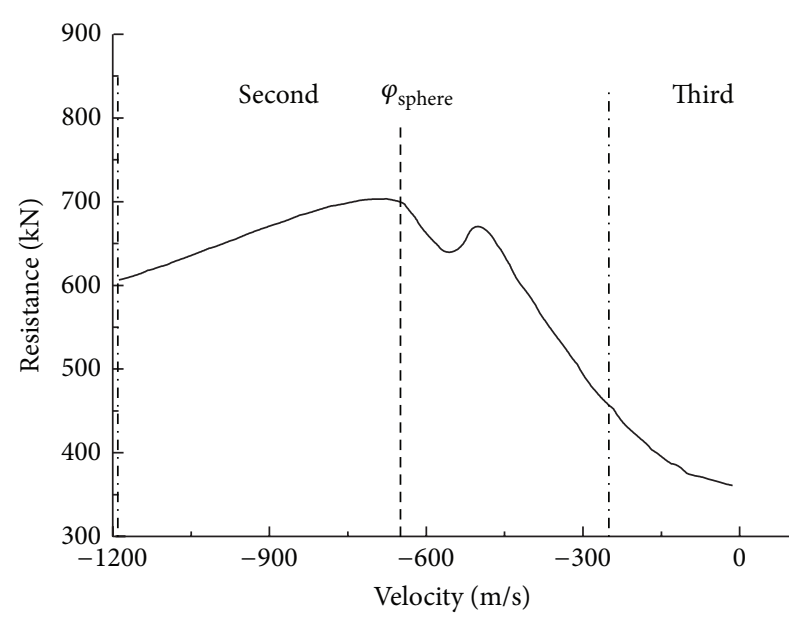

(a) Penetration resistance versus velocity

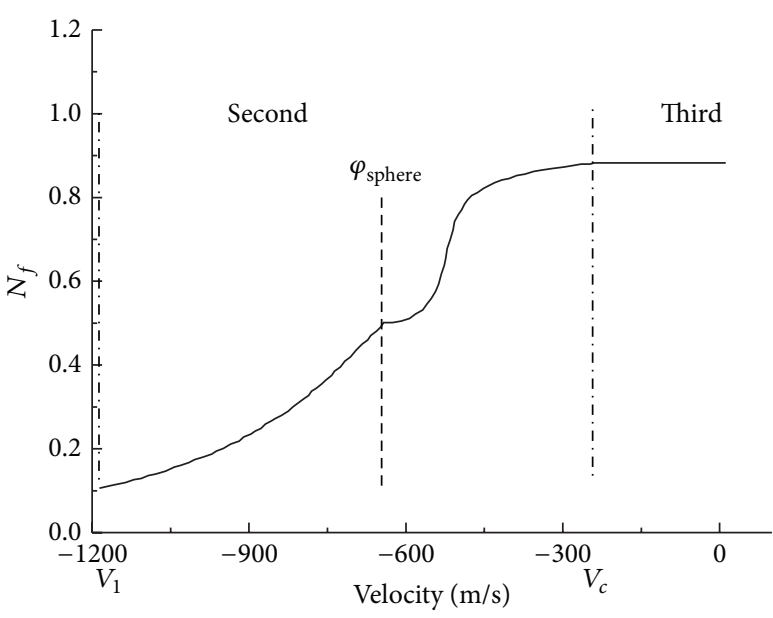

(b) Nose shape coefficient versus velocity

FIGURE 11: Variation curve of resistance in second part of the interval.

Figure 10 shows that spherical-nose is the dividing point of the variation in nose shape coefficient. The shapes on the two sides of the dividing point are ogive-nose and blunt-nose. To investigate the characteristics of the second part $\left[V_{1}, V_{c}\right]$, we plot Figure 11 by considering resistance and nose shape coefficient versus penetration at a velocity of $1201 \mathrm{~m} / \mathrm{s}$ and $\omega=$ 0.8 as well as $821 \mathrm{~m} / \mathrm{s}$ and $\omega=0.9$.

For an ogive-nose projectile in the second part of the interval (Figure 10), the curves of nose shape coefficients and penetration resistance change smoothly. In a highvelocity phase, the increasing effect on resistance caused by variation in nose shape coefficients is more evident than the decreasing effect caused by variation in velocity (Figure 11), so the resistance keeps increasing. In low-velocity phase, the velocity is dominant, so the resistance keeps decreasing (Figure 12). For a spherical-nose projectile, the curve of the variation in nose shape coefficients influences resistance. In a low-velocity phase, the variation in resistance is irregular. In a high-velocity phase, resistance continuously decreases because of the main role of velocity in early stage; as nose shape coefficient becomes dominant, resistance increases. Resistance unlikely decreases until velocity becomes dominant again. Resistance is determined by nose shape coefficient and velocity; in different phases, these variables elicit different effects. For instance, the curve of resistance exhibits double peaks in a high-velocity penetration and when the shape of the nose changes to blunt because of a sudden variation in nose shape coefficients; this effect negatively influences penetration performance and acceleration. If possible, sphericalnose and blunt-nose should be avoided.

\section{Conclusions}

We present a mass loss penetration model to investigate the dynamic response of a projectile penetrating concrete target. The model is divided into three stages: cratering phase, mass loss penetration phase, and remainder rigid projectile penetration phase. Our quadratic polynomial data of mass loss rate agrees with the experimental data at a greater extent than linear data. The projectile mass loss is attributed to 


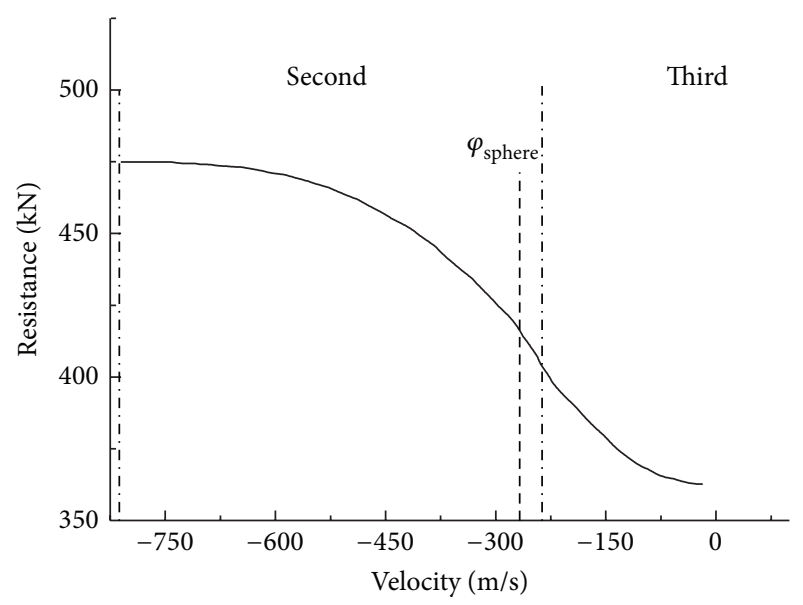

(a) Penetration resistance versus velocity

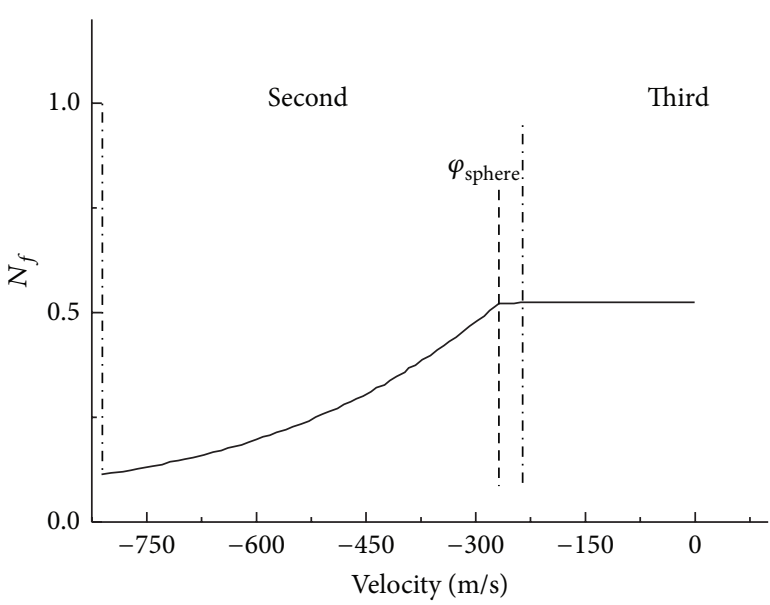

(b) Nose shape coefficient versus velocity

FIGURE 12: Variation curve of resistance in second part of the interval at low velocity.

the nose abrasion; nose mass loss is approximately $60 \%$ to $80 \%$ of body mass loss; the mass abrasion model is close to the rigid penetration model when $\omega \rightarrow 0$; CRH decreases as initial impact velocity increases; and nose shape is also transformed from an ogive-like structure to sphere- or bluntlike structure. The nose shape coefficients change because of the variation in nose shape and $\mathrm{CRH}$; thus, penetration resistance varies. With this variation, velocity, acceleration, and the relationship of DOP and initial impact velocity also change. Simple projectile mass loss has influences on penetration depth but the effect is not significant; penetration resistance is the main factor. Penetration resistance is determined by nose shape coefficient and velocity; in different phases, these variables elicit different effects. To improve the penetration performance, spherical-nose and blunt-nose should be avoided.

\section{Conflict of Interests}

The authors declare that there is no conflict of interests regarding the publication of this paper.

\section{Acknowledgments}

The authors would like to acknowledge Yu Ma, Junjie Gong, and Longwen $\mathrm{Wu}$ for their technical supports.

\section{References}

[1] C. E. Anderson Jr. and S. R. Bodner, "Ballistic impact: the status of analytical and numerical modeling," International Journal of Impact Engineering, vol. 7, no. 1, pp. 9-35, 1988.

[2] G. G. Corbett, S. R. Reid, and W. Johnson, "Impact loading of plates and shells by free-flying projectiles: a review," International Journal of Impact Engineering, vol. 18, no. 2, pp. 141-230, 1996.

[3] S. J. Brown, "Energy release protection for pressurized systems. Part II: review of studies into impact terminal ballistics," Applied Mechanics Reviews, vol. 39, no. 2, pp. 177-201, 1986.
[4] M. J. Forrestal, B. S. Altman, J. D. Cargile, and S. J. Hanchak, "An empirical equation for penetration depth of ogive-nose projectiles into concrete targets," International Journal of Impact Engineering, vol. 15, no. 4, pp. 395-405, 1994.

[5] M. J. Forrestal and D. Y. Tzou, "A spherical cavity-expansion penetration model for concrete targets," International Journal of Solids and Structures, vol. 34, no. 31-32, pp. 4127-4146, 1997.

[6] M. J. Forrestal, D. J. Frew, J. P. Hickerson, and T. A. Rohwer, "Penetration of concrete targets with deceleration-time measurements," International Journal of Impact Engineering, vol. 28, no. 5, pp. 479-497, 2003.

[7] D. J. Frew, M. J. Forrestal, and J. D. Cargile, "The effect of concrete target diameter on projectile deceleration and penetration depth," International Journal of Impact Engineering, vol. 32, no. 10, pp. 1584-1594, 2006.

[8] M. J. Forrestal, D. J. Frew, S. J. Hanchak, and N. S. Brar, "Penetration of grout and concrete targets with ogive-nose steel projectiles," International Journal of Impact Engineering, vol. 18, no. 5, pp. 465-476, 1996.

[9] F. R. Norwood, "Cylindrical cavity expansion in a locking soil," Tech. Rep. SLA-74-0201, Sandia Laboratories, 1974.

[10] M. R. Huang, X. H. Gu, and Y. H. Gao, "Cavity expansion model based on the Griffth strength theory and its application," Mechanics in Engeering, vol. 31, no. 5, pp. 30-34, 2009.

[11] J. B. Xu, Investigations on Long Projectiles Penetrating into Concrete Targets, National University of Defense Technology, Changsha, China, 2001.

[12] S. Mastilovic and D. Krajcinovic, "Penetration of rigid projectiles through quasi-brittle materials," Journal of Applied Mechanics, vol. 66, no. 3, pp. 585-592, 1999.

[13] J. Sternberg, "Material properties determining the resistance of ceramics to high velocity penetration," Journal of Applied Physics, vol. 65, no. 9, pp. 3417-3424, 1989.

[14] M. J. Forrestal, D. Y. Tzou, E. Askari, and D. B. Longcope, "Penetration into ductile metal targets with rigid spherical-nose rods," International Journal of Impact Engineering, vol. 16, no. 56, pp. 699-710, 1995.

[15] H. Zhou, Elastoplastic Material in the Cavity Expansion Theory and Its Applications in Penetration Mechanics, University of Chinese Academy of Sciences, He Fei, China, 2004. 
[16] Y. B. Wang, Y. Y. Zhu, M. H. Yu et al., "Based on the unified strength theory of high velocity tungsten projectile body penetrating ceramic targets," Explosion and Shock Waves, vol. 24, no. 6, pp. 534-540, 2004.

[17] M. H. Yu, Twin Shear Theory and Its Application, Science Press, Beijing, China, 1998.

[18] X. W. Chen and Q. M. Li, "Deep penetration of a nondeformable projectile with different geometrical characteristics," International Journal of Impact Engineering, vol. 27, no. 6, pp. 619-637, 2002.

[19] X.-W. Chen and J.-C. Li, "Analysis of penetration depth and resistive force in the deep penetration of a rigid projectile," Explosion and Shock Waves, vol. 29, no. 6, pp. 584-589, 2009.

[20] X. W. Chen, S. C. Fan, and Q. M. Li, "Oblique and normal perforation of concrete targets by a rigid projectile," International Journal of Impact Engineering, vol. 30, no. 6, pp. 617-637, 2004.

[21] X. W. Chen, X. Y. Li, Y. Z. Chen et al., "The third dimensionless parameter in the penetration dynamics of rigid projectiles," Acta Mechanica Sinica, no. 1, pp. 77-84, 2007.

[22] X. W. Chen, "Mechanical design of dynamic deep penetrator (I): analysis of Penetration theory," Explosion and Shock Waves, vol. 25, no. 6, pp. 499-505, 2005.

[23] X. W. Chen, F. J. Zhang, S. Q. Yang et al., "Mechanical design of dynamic deep penetrator (III): analysis of shrinkage experiment," Explosion and Shock Waves, vol. 26, no. 2, pp. 105114, 2006.

[24] X. W. Chen and J. M. Jin, "Mechanical design of dynamic deep penetrator (II): the relevant mechanical analysis and examples of the target," Explosion and Shock Waves, vol. 26, no. 1, pp. 7178, 2006.

[25] X. W. Chen, F. J. Zhang, R. Z. Xie et al., “The experiment of $\phi$ $25 \mathrm{~mm}$ small size shrinkage ratio penetrator," Annals of Science and Technology Academy of Engineering Physics, no. 1, pp. 110111, 2004.

[26] S. A. Silling and M. J. Forrestal, "Mass loss from abrasion on ogive-nose steel projectiles that penetrate concrete targets," International Journal of Impact Engineering, vol. 34, no. 11, pp. 1814-1820, 2007.

[27] C. E. Anderson Jr., "From fire to ballistics: a historical retrospective," International Journal of Impact Engineering, vol. 29, no. 110, pp. 13-67, 2003.

[28] U. Gerlach, "Microstructural analysis of residual projectiles-a new method to explain penetration mechanisms," Metallurgical Transactions A, vol. 17, no. 3, pp. 435-442, 1986.

[29] D. A. Shockey, A. H. Marchand, S. R. Skaggs, G. E. Cort, M. W. Burkett, and R. Parker, "Failure phenomenology of confined ceramic targets and impacting rods," International Journal of Impact Engineering, vol. 9, no. 3, pp. 263-275, 1990.

[30] D. J. Frew, S. J. Hanchak, M. L. Green, and M. J. Forrestal, "Penetration of concrete targets with ogive-nose steel rods," International Journal of Impact Engineering, vol. 21, no. 6, pp. 489-497, 1998.

[31] S. R. Beissel and G. R. Johnson, "A three-dimensional abrasion algorithm for projectile mass loss during penetration," International Journal of Impact Engineering, vol. 27, no. 7, pp. 771-789, 2002.

[32] J. Zhao, F. N. Jin, and Y. Xu, "Study on the DOP KE penetrator with including the effect of mass abrasion," in Proceedings of the 25th International Symposium on Ballistics, pp. 1132-1139, 2010.

[33] C. E. Anderson Jr., "From fire to ballistics: a historical retrospective," International Journal of Impact Engineering, vol. 29, no. 110, pp. 13-67, 2003.
[34] Y. N. Wang, F. L. Huang, H. J. Wu et al., "Study on the mass loss and variation of nose shape of ogive-nose high-speed projectile penetrate concrete target," in Proceedings of the Seminar of Anti Deep/Multilayer Target, pp. 146-154, Sanya, China, 2010.

[35] J. Zhao, X. W. Chen, F. N. Jin, and Y. Xu, "Depth of penetration of high-speed penetrator with including the effect of mass abrasion," International Journal of Impact Engineering, vol. 37, no. 9, pp. 971-979, 2010. 


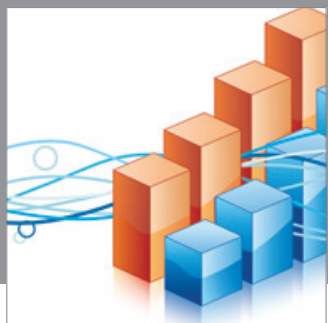

Advances in

Operations Research

mansans



The Scientific World Journal

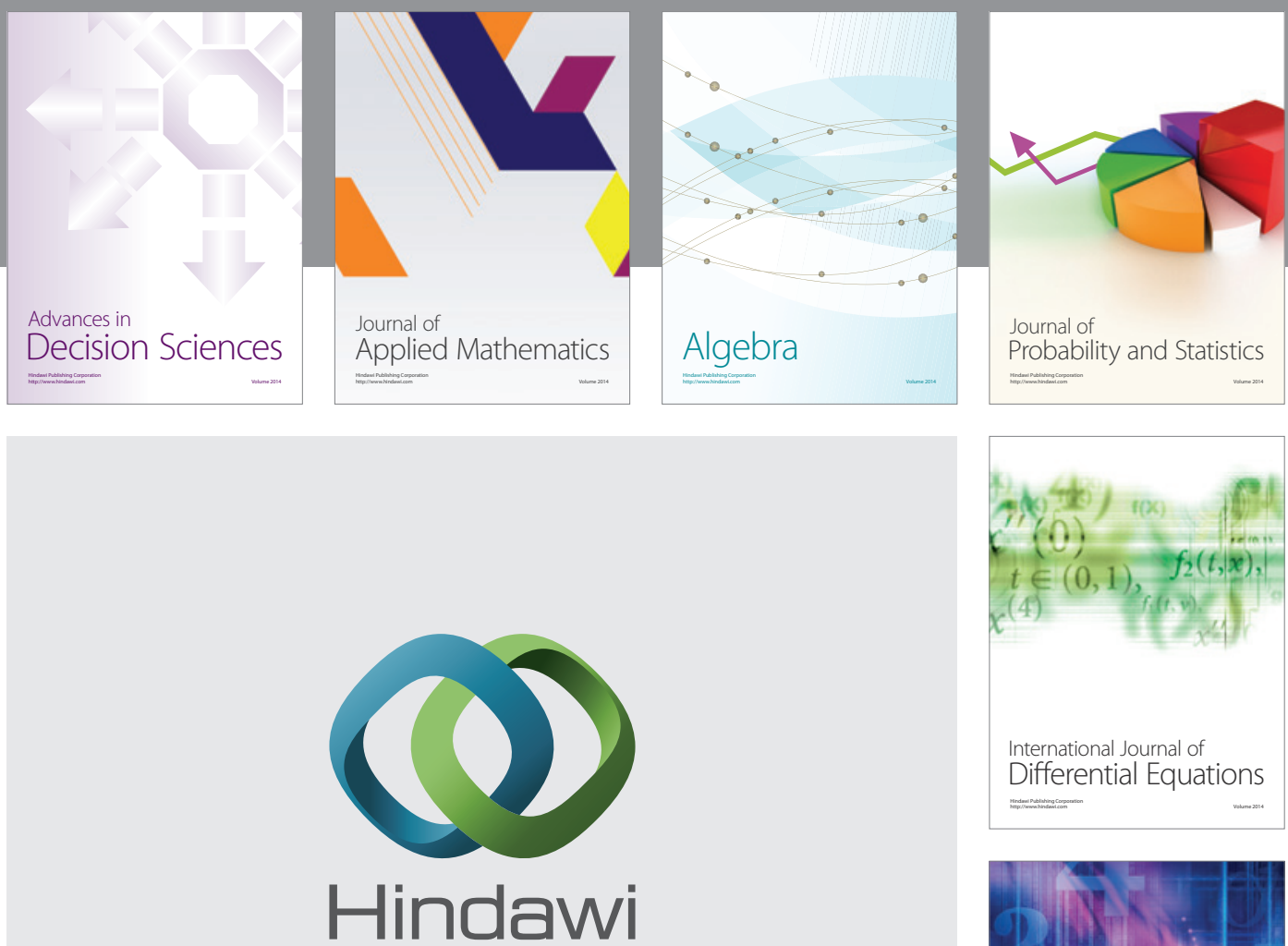

Submit your manuscripts at http://www.hindawi.com


Journal of

Function Spaces

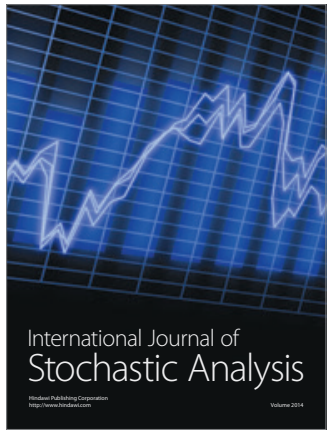

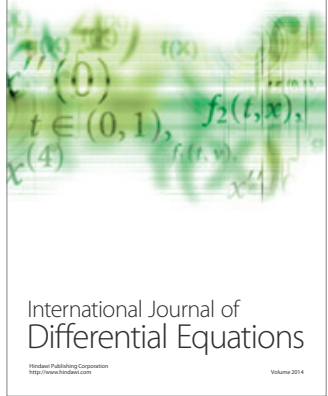
